\title{
Características histológicas e histoquímicas del intestino delgado en crías de la tortuga caguama (Caretta caretta)
}

Rodrigo Ontiveros Tlachia,1

Fernando Alberto Muñoz Tenería Santiago René Anzaldúa Arce ${ }^{\text {a* }}$

a Departamento de Morfologia, Facultad de Medicina Veterinaria y Zootecnia, Universidad Nacional Autónoma de México,

Coyoacán 04510, México D.F., México.

b Facultad de Agronomía y Veterinaria, Universidad Autónoma de San Luis Potosí, Km 14.5, Carretera San Luis Potosi-Matehuala, Ejido Palma de la Cruz, Soledad de Graciano Sánchez, San Luis Potosí 78321, San Luis Potosí, México.

${ }^{1}$ Este artículo es el resultado del trabajo del primer autor durante su estancia en el Programa de Iniciación Temprana a la Investigación Científica con el propósito de obtener el título de Médico Veterinario Zootecnista.

*Autor para correspondencia: Tel: + 525556225893

Correo electónico:

reneanzalduaarce@yahoo.com.mx

Recibido: 2014-05-12 Aceptado: $2014-09-17$ Publicado: $2014-09-29$ Información y declaraciones adicionales en la página 13

(a) Derechos de autor: Rodrigo Ontiveros Tlachi et al. 2014 acceso abierto $\boldsymbol{\varnothing}$

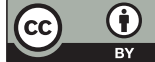

Distribuido bajo una Licencia Creative Commons Atribución 4.0 Internacional (CC-BY 4.0

\section{Resumen}

La tortuga caguama (Caretta caretta) es una especie amenazada, por tanto la [investigación básica] es esencial para complementar los esfuerzos de conservación. Con el objeto de generar información en este campo, este trabajo se orientó a la identificación de la morfología microscópica y los aspectos histoquímicos del intestino delgado en crías de tortuga caguama. Debido a su estatus como especie amenazada, se analizaron 4 especímenes muertos. Durante la necropsia, se obtuvieron muestras del intestino delgado en las porciones craneal y caudal. Las muestras se procesaron por el método de inclusión en parafina y se tiñeron por las siguientes técnicas: hematoxilina y eosina, tricrómica de Gomori, ácido peryódico-reactivo de Schiff (PAS), azul alciano ( $\mathrm{pH} 1.0$ y pH 2.5), PAS-azul alciano, azul de toluidina $(\mathrm{pH} 4.5$ y pH 3.5), Giemsa, hierro coloidal, azul de Perls, impregnación de Wilder, metenamina de plata, Grimelius y Masson-Fontana.

Entre los hallazgos histológicos, los principales fueron: la mucosa intestinal presentó plicas revestidas por un epitelio cilíndrico pseudoestratificado con vasos sanguíneos y en la submucosa se observaron abundantes vasos linfáticos. Los gránulos de secreción de las células caliciformes presentaron las siguientes características: en la porción craneal se observó la presencia de mucopolisacáridos neutros, ácidos sulfatados y con ácido siálico. En la porción caudal se detectó la presencia de mucopolisacáridos neutros y con ácido siálico. A lo largo del intestino se observaron células argentafines, principalmente en la porción craneal. Existen diferencias morfológicas, tanto histológicas como histoquímicas, entre la porción craneal y caudal en el intestino de C. caretta. Estas características se correlacionaron con posibles funciones dentro de la fisiología tisular.

Palabras clave: Caretta caretta; Histología; Histoquímica; Intestino delgado; Mucopolisacáridos; Células argentafines. 


\section{Introducción}

Las tortugas marinas pertenecen a la clase Reptilia y sus primeros registros fósiles datan de hace 200 millones de años (Pritchard, 1979). Pertenecen al orden Testudines (Linnaeus, 1758), el cual incluye a la familia Cheloniidae (Oppel, 1811). Existen 7 especies de tortugas marinas, entre las que se encuentra la tortuga caguama (ITIS, 2000).

Las tortugas caguama presentan una amplia distribución biogeográfica: habitan las zonas cálidas del Océano Pacífico, el Océano Atlántico, el Océano Índico y el Mar Mediterráneo (Spotila, 2004). Son una especie omnívora, que se alimenta de moluscos, crustáceos, esponjas, corales, algas y vertebrados pequeños como peces (Ernst y Lovich, 2009). Tienen hábitos de alimentación y nado bentónicos (Davenport y Clough, 1986, Ernst y Lovich, 2009); a temprana edad (cuando su peso se encuentra entre los $300 \mathrm{~g}$ y $400 \mathrm{~g}$ ), pueden nadar a profundidades mayores de los 2 m; como adultos, pueden hallarse alimentándose a 290 m (Davenport y Clough, 1986).

En las tortugas caguama, como en otros reptiles, el tracto gastrointestinal (TGI) consiste en la cavidad oral, el esófago, el estómago, los intestinos, tanto delgado como grueso, y la cloaca (Wyneken, 2001). El intestino delgado (ID) conforma alrededor de 50\% del total del TGI (Thompson, 1980); se divide en duodeno, yeyuno e íleon. Macroscópicamente, el duodeno tiene una apariencia de panal de abejas (Wyneken, 2001). La digestión química inicia en el estómago y continúa en el ID, donde serán añadidas enzimas que digerirán a los carbohidratos y proteínas. El ID está especializado en la absorción de aminoácidos, carbohidratos, ácidos grasos, minerales (principalmente calcio y fósforo) y agua (Wyneken, 2001).

De acuerdo con los datos de la investigación, no se han realizado descripciones ni histológicas ni histoquímicas del ID de las tortugas caguama. Con el objeto de generar información en este campo, este análisis consistió en identificar la morfología microscópica y los aspectos histoquímicos del intestino delgado en crías de tortuga caguama y los resultados se correlacionaron con posibles funciones. El ID, visto como un órgano especializado relacionado con la digestión y absorción de nutrimentos, fue el objetivo de esta investigación, como una primera aproximación, si se considera su uso potencial en estudios de fisiología y patología digestiva.

\section{Material y métodos Materiales biológicos}

El protocolo para el uso de animales fue aprobado por el Comité Institucional de Cuidado y Uso de Animales de Experimentación (CICUAE) de la Facultad de Medicina Veterinaria y Zootecnia (FMVZ) de la Universidad Nacional Autónoma de México, además de seguirse los lineamientos del Parque Eco-arqueológico Xcaret.

Por tratarse de una especie amenazada, el estudio se desarrolló con tortugas caguama,muertas, en concordancia con las recomendaciones señaladas por el CICUAE. En el trabajo de campo colaboró la Coordinación de Tortugas Marinas y Manatís del Parque Ecoarqueológico Xcaret, localizado en Quinana Roo, México, a los $21^{\circ} 09^{\prime} 17^{\prime \prime} \mathrm{N}$ y $86^{\circ} 50^{\prime} 56^{\prime \prime} \mathrm{O}$.

En el trabajo de campo, llevado a cabo de junio a julio de 2010, se practicaron diversas necropsias; sin embargo, solo en 4 individuos se cumplieron las caracterís- 
ticas deseadas para esta investigación $(n=4)$, pues se consideró que el tiempo entre la muerte y la fijación fuera menor a una hora y que no existieran alteraciones macroscópicas. Los especímenes utilizados se incubaron en nidos artificiales dentro del acuario de Xcaret y se hallaron muertos después de la eclosión. Al examen post mórtem, no se observaron lesiones macroscópicas. Durante la necropsia, el ID de cada tortuga se dividió exactamente por la mitad. Se obtuvieron dos porciones: craneal (duodeno) y caudal (yeyuno/íleon), debido a la dificultad de distinguir macroscópicamente entre los segmentos intestinales, tal como lo reporta Magalhaes (2012). El tiempo transcurrido entre la muerte y la fijación fue alrededor de 30 minutos.

\section{Procesamiento histológico}

Las muestras se fijaron durante 48 horas en Z-Fix ${ }^{\circledR}$ (Anatech Ltd., MI, USA), una solución tamponada de zinc-formalina. Después se procesaron por el método de inclusión en parafina Paraplast $\AA$ ("R", McCormick Scientific $®$ IL, USA) mediante un histoquinette (American Optical ${ }^{\circ}$ T/P 8000): las muestras se cortaron con un micrótomo (Leica ${ }^{\circledR}$ RM 2125 RT) en láminas de $4 \mu \mathrm{m}$ de grosor; se adhirieron a portaobjetos, desparafinados en xilol ( 5 minutos en dos ocasiones); se rehidrataron con soluciones decrecientes de etanol (100\%-95\%, 5 minutos en dos ocasiones), y se lavaron en solución tamponada de fosfatos (PBS) por 5 minutos.

Para el análisis histológico básico se manejaron las siguientes técnicas: hematoxilina y eosina (HE) y tricrómica de Gomori (TG) (García del Moral, 1993). Mientras que para el estudio histoquímico se hicieron tinciones especiales (Pearse, 1960, García Del Moral, 1993, Prophet et al, 1995), como la técnica del ácido peryódico-reactivo de Schiff (PAS), Giemsa, azul de toluidina (AT) a pH 4.5 y pH 3.5, azul alciano (AA) 8GX a pH 1.0 y pH 2.5, PAS/AA (AA 8GX pH 2.5/ácido peryódico-reactivo de Schiff), hierro coloidal, azul de Perls, metenamina de plata (MP), impregnación de Wilder (IW) (Prophet et al, 1995), Grimelius y Masson-Fontana (M-F). Para el montaje se utilizó Permanent Mounting Medium (VectaMount ${ }^{\circledR}$ H-5000 CA, USA). La intensidad de la tinción se percibió visualmente bajo los siguientes parámetros: (-) sin tinción, (+-) intensidad muy débil, (+) intensidad débil, $(++)$ intensidad media, $(+++)$ intensidad fuerte y $(\gamma-\mathrm{M})$ gam a-metacromasia (García del Moral, 1993).

\section{Procesamiento de imágenes}

Las fotomicrografías se tomaron con un microscopio Carl Zeiss ${ }^{\circledR}$ (Primo Star ${ }^{\circledR}$, Göttingen, Germany) conectado a una cámara digital Moticam $5 \AA$ (Motic ${ }^{\circledR}$, Xiamen, China). Para las mediciones se empleó el software Motic Image Plus ${ }^{\circledR}$ software (Motic ${ }^{\circledR}$, Version 2.0, Xiamen, China).

\section{Nomenclatura}

La nomenclatura utilizada está adecuada a la Nómina Anatómica Veterinaria quinta edición (ICVGAN, 2012). 


\section{Resultados}

\section{Resultados de histología}

La mucosa consiste en el epitelio de revestimiento, lámina propia y la muscular de la mucosa. El epitelio de revestimiento en el TGI de las tortugas caguama es pseudoestratificado cilíndrico con células caliciformes intercaladas (CC), que se notan en mayor número en la porción craneal (Figuras $1 C, 1 D, 1 G$ y $1 H$ ). Se observó que las CC de esta porción tienen forma alargada típica, como un cáliz, en contraste con la porción caudal, donde son redondeadas y de menor tamaño.

Los enterocitos (células epiteliales) presentaron un borde estriado (Figuras TC, ID, $1 G$ y $1 H$ ); además, en ellos se advirtieron vasos sanguíneos abundantes en la lámina propia (Figura 1G). Debajo de la membrana basal se encuentra la lámina propia, delimitada por la muscular de la mucosa que se evaginó y se formaron plicas con diferentes longitudes. El tamaño de estas plicas fue mayor en la porción craneal (Figuras TA y TE). Éstas evaginaciones se confirmaron con la tinción TG, que permite distinguir el tejido conjuntivo del músculo liso (Figuras TC y $1 G$ ).

Del mismo modo, se distinguieron múltiples membranas basales que soportan un epitelio plano simple (endotelio) y forman ductos, semejantes a vasos linfáticos (Figuras $1 C, 1 F$ y $1 H$ ). Además, se apreciaron células de afinidad tintorial pálida de núcleo central y uno o dos nucléolos en el tejido conjuntivo laxo adyacente a la lámina muscular de la mucosa.

La tunica muscularis (muscular del órgano) consiste de 2 capas de músculo liso: el estrato circular, que fue el más delgado, y el estrato longitudinal (Figuras TA, IB, IE y IF). Entre las capas musculares circular y longitudinal se localizaron grupos de células de afinidad tintorial pálida y núcleo central (Figuras IB y TF). La serosa, formada por tejido conjuntivo laxo areolar y un mesotelio, recubría la superficie externa a lo largo del intestino (Figura 1B).

\section{Resultados de histoquímica}

Se verificaron variaciones importantes. Los resultados de la histoquímica de los mucopolisacáridos (MPS) se muestran en el cuadro 1.

La tinción PAS, que detecta glucógeno y dioles vecinales reactivos con el peryodato (Mc Manus, 1948), confirmó que el epitelio de revestimiento es pseudoestratificado cilíndrico (Figuras 2A y $3 \mathrm{~A}$ ). El citoplasma apical de las CCs dio positivo a PAS a lo largo del TGI (Figuras 2A, 3A y Tabla 1). En la submucosa, las membranas basales que sostenían el endotelio, en particular, se tiñeron con las tinciones PAS, MP e IW (Figuras 2A, 2E, 2F, 3A, 3E y 3F respectivamente).

Se observó una reacción de metacromasia con las tinciones Giemsa y AT a pH 4.5, que se corroboró con la tinción AT a pH 3.5, reacción que se resistió a la deshidratación etílica; por lo tanto, pertenece al tipo gamma, pues demostró la presencia de ésteres de sulfato (Pearse, 1960, García de Moral, 1993). Se descubrió una reacción metacromática en la porción craneal (Figs. 2B, 2C, 2D y Tabla 1), pero no en la porción caudal, donde la tinción fue negativa (Figuras 3B, 3C, 3D y Tabla 1).

La tinción AA se usó para determinar la presencia de mucopolisacáridos ácidos (MPSA) (Mowry, 1956); AA a pH 1.0, para MPSA con ésteres O-sulfatados, y AA a pH 2.5, para MPSA con ésteres O-sulfatados y MPSA con grupos carboxílicos (ácido siálico o urónico) (Pearse, 1960, García del Moral, 1993). 


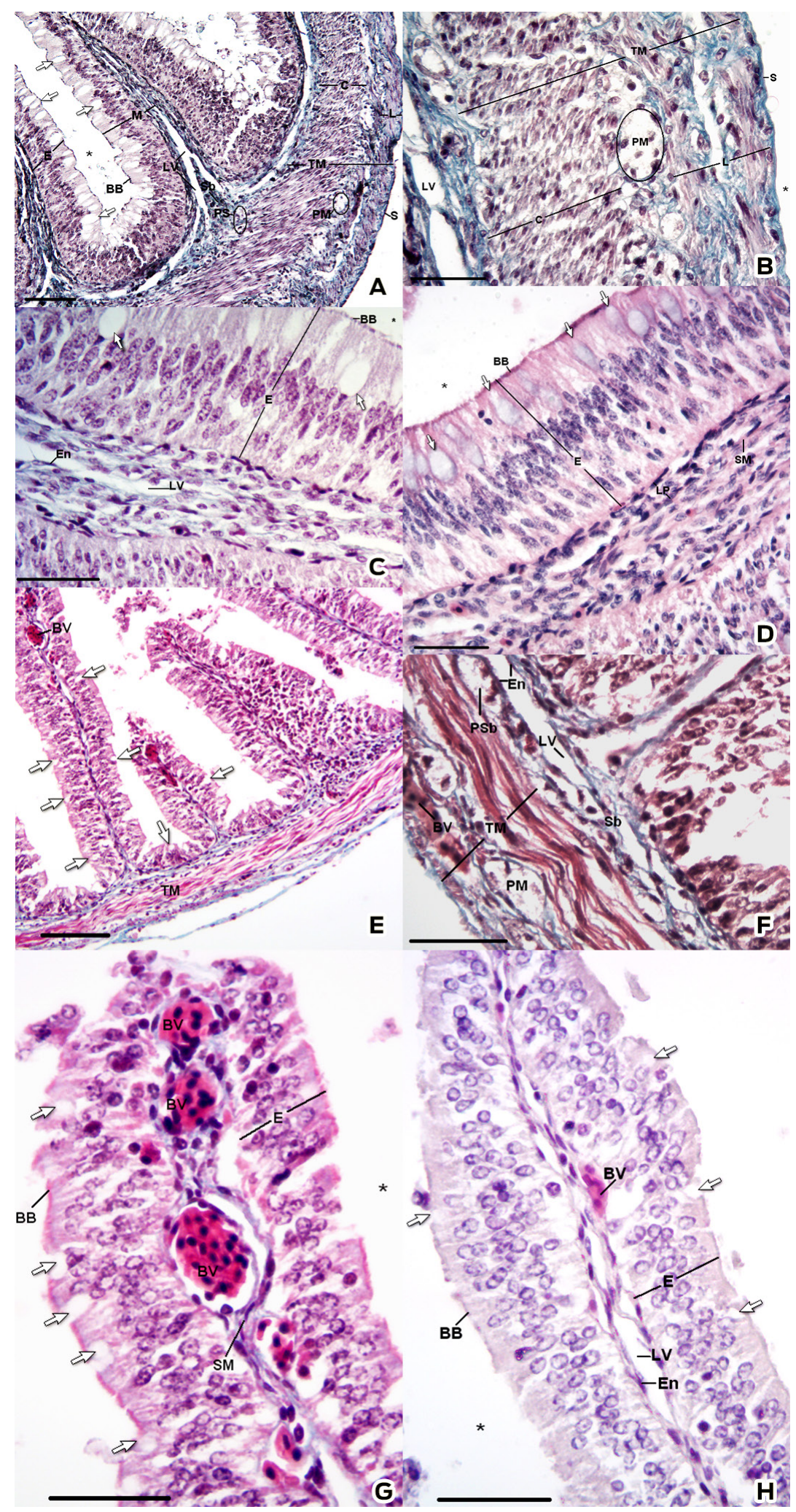

Figura 1. Características histológicas del intestino delgado. A, B, C, E, F y G: Tinción tricrómica de Gomori. D y H: Tinción hematoxilina y eosina. Epitelio de revestimiento (E), mucosa (M), submucosa (Sb), músculo liso (SM), tunica muscularis (TM), serosa (S), células caliciforme (flecha), borde estriado (BB), vaso sanguíneo (BV), vaso linfático (LV), endotelio (En), plexo mientérico (PM) y lumen $\left({ }^{*}\right)$. Barra: A y E) $100 \mu \mathrm{m} ; \mathrm{B}, \mathrm{C}, \mathrm{D}, \mathrm{F}$ y G) $30 \mu \mathrm{m}$. 
Cuadro 1. Resumen de los resultados histoquímicos de las células caliciformes.

\begin{tabular}{|c|c|c|}
\hline Técnicas empleadas & Porción craneal & Porción caudal \\
\hline PAS & +++ & +++ \\
\hline Azul alciano $(\mathrm{pH} 1.0)$ & + & +- \\
\hline Azul alciano (pH 2.5) & + & +++ \\
\hline Azul alciano/PAS & +++ & +++ \\
\hline Giemsa & $++\gamma-\mathrm{M}$ & - \\
\hline Azul de toluidina $(\mathrm{pH}$ 4.5) & $++\gamma-\mathrm{M}$ & - \\
\hline Azul de toluidina $(\mathrm{pH}$ 3.5) & $++\gamma-\mathrm{M}$ & - \\
\hline Metenamina de plata & ++ & +++ \\
\hline Hierro coloidal & + & +++ \\
\hline Azul de Perls & - & - \\
\hline
\end{tabular}

(-) sin tinción, (+-) intensidad muy débil, (+) intensidad débil, (++) intensidad media, $(+++)$ intensidad fuerte y $(\gamma-M)$ gama-metacromasia.

En las muestras de la porción craneal teñidas con AA a pH 1.0, los gránulos de las CC se pigmentaron débilmente (Figura 2G). Mientras que los gránulos de algunas CC en la porción caudal tuvieron una muy débil coloración, algunos otros fueron negativos (Figura 3G). Las muestras de la porción craneal teñidas con AA a pH 2.5 mostraron una reacción tenue en los gránulos de las CC (Figura 2H), mientras que en la porción caudal los gránulos se pigmentaron intensamente (Figura 3H).

La técnica del PAS/AA permite distinguir entre gránulos con MPS neutros y MPSA en la misma célula. Detecta MPSA con grupos carboxílicos y MPSA con ésteres $O$-sulfatados (color turquesa), dioles vecinales reactivos al peryodato (color magenta) y MPSA con grupos carboxílicos, MPSA con ésteres O-sulfatados y dioles vecinales reactivos al peryodato en conjunto (color morado) (Yamabayashi, 1987). Los gránulos de las CC en ambas porciones intestinales mostraron afinidad a los dos colorantes, pero con diferente distribución. En la porción craneal, las CC mostraron gránulos específicos; incluso fue posible distinguir su afinidad por la tinción PAS o AA (Figura 2l). En contraste, en la mitad caudal se observó una pigmentación homogénea con ambos colorantes de tono morado (Figura 3I).

Mediante la tinción de hierro coloidal se observaron MPS con ácido siálico (Pearse, 1960; Rambourg, 1972; García del Moral, 1993) en gránulos de las CC a lo largo del TGl (Figuras 2J, 3J y cuadro 1). La porción craneal mostró una coloración menor (Figura 2J) a la porción caudal (Figura 3J). Este resultado se corroboró con la tinción azul de Perls, que descarta falsos positivos: las CC no se pigmentaron (García del Moral, 1993) (Figuras 2K, 3K y cuadro 1).

La tinción MP y la IW, que evidenció fibras reticulares de la lamina reticularis (Figuras 2E, 2F, 3E y 3F), se emplearon para determinar la presencia de membranas basales. La tinción MP demostró, además de la presencia de múltiples membranas basales, afinidad por vesículas citoplasmáticas en los enterocitos, adicionalmente a los gránulos de las CC en ambas porciones intestinales, con mayor intensidad en la porción caudal (Figuras 2E y 3E).

La tinción Grimelius, una técnica de impregnación de plata, se empleó para la detección de células con gránulos argirófilos (Grimelius, 2004). Acúmulos de células agrupadas se encontraron en la submucosa, en particular en la base de 


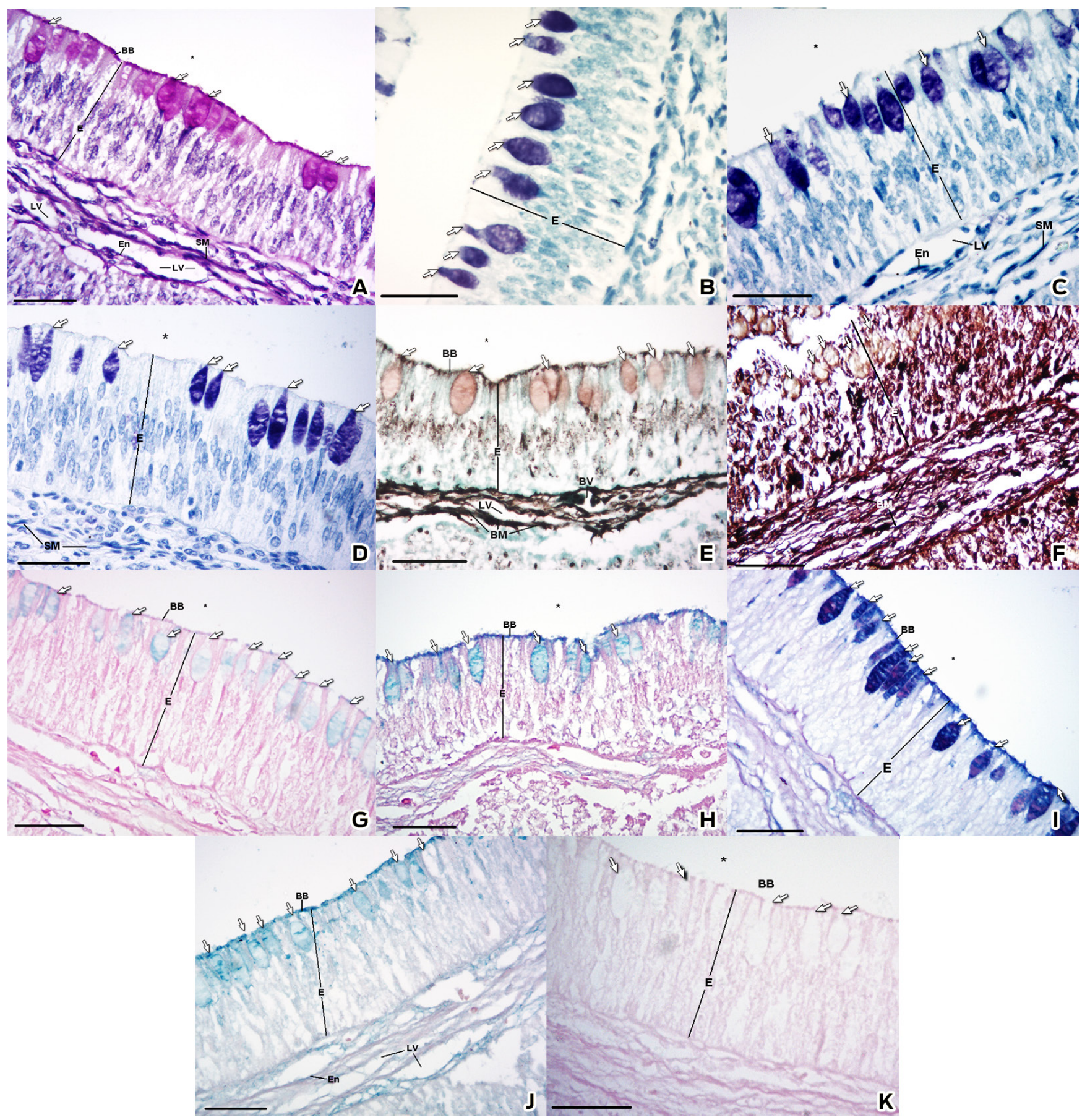

Figura 2. Características histoquímicas de la porción craneal del intestino delgado. A) Tinción PAS. B) Tinción Giemsa. C) Tinción azul de toluidina (pH 4.5). D) Tinción azul de toluidina (pH 3.5). E) Tinción metenamina de plata. F) Impregnación de Wilder. G) Tinción azul alciano (pH 1.0). H) Tinción azul alciano (pH 2.5). I) Tinción azul alciano/PAS. J) Tinción de hierro coloidal. K) Tinción azul de Perls. Epitelio de revestimiento (E), borde estriado (BB), célula caliciforme (flecha), membrana basal (BM), músculo liso (SM), vaso sanguíneo (BV), vaso linfático (LV), endotelio (En), tunica muscularis (TM) y lumen $(*)$. Barra: $30 \mu \mathrm{m}$. 


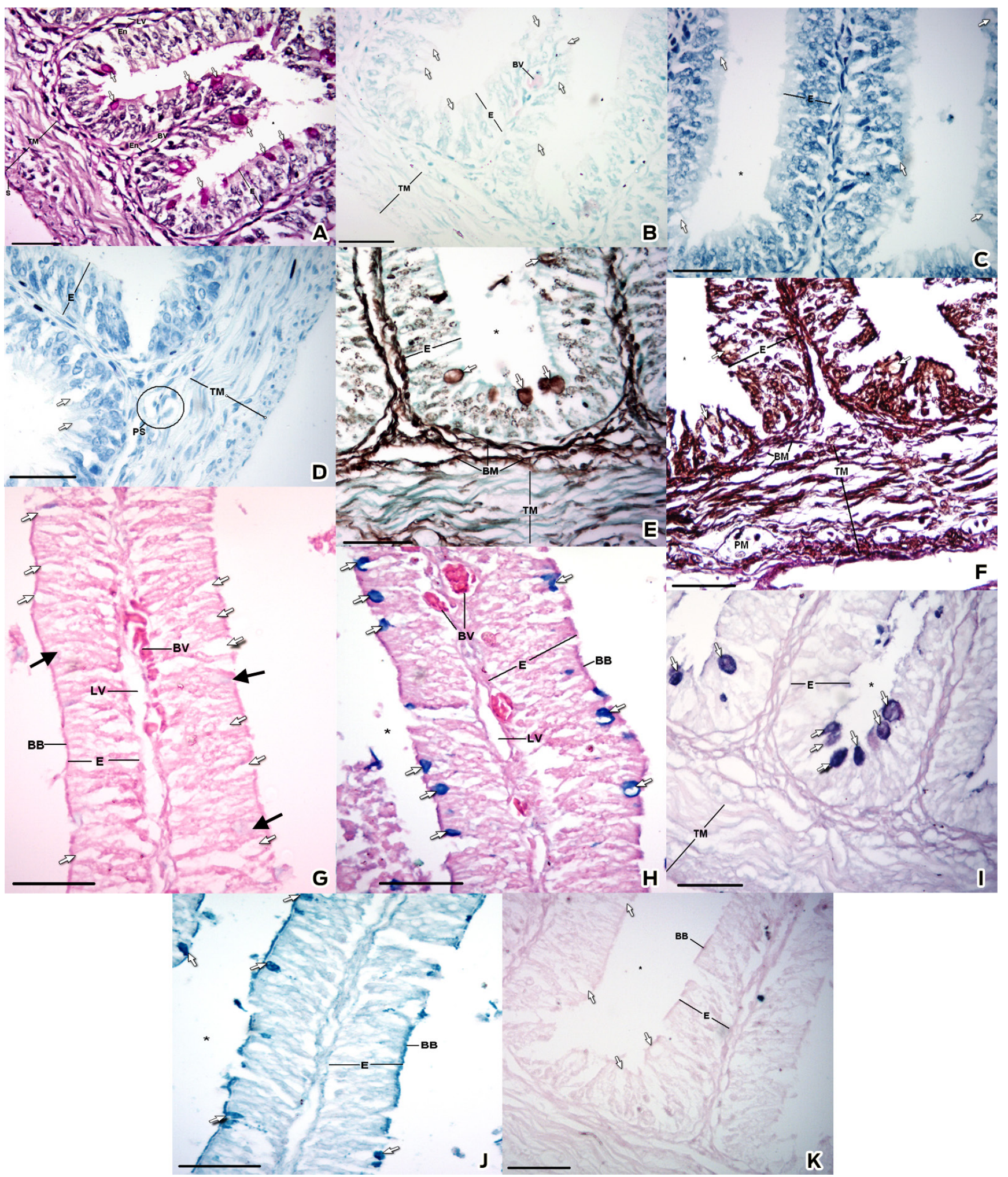

Figura 3. Características histoquímicas de la porción caudal del intestino delgado. A) Tinción PAS. B) Tinción Giemsa. C) Tinción azul de toluidina (pH 4.5). D) Tinción azul de toluidina (pH 3.5). E) Tinción metenamina de plata. F) Impregnación de Wilder. G) Tinción azul alciano ( $\mathrm{pH}$ 1.0). H) Tinción azul alciano ( $\mathrm{pH}$ 2.5). I) Tinción azul alciano/PAS. J) Tinción de hierro coloidal. K) Tinción azul de Perls. Epitelio de revestimiento (E), borde estriado (BB), célula caliciforme (flecha), célula caliciforme teñida con AA pH 1.0 (flecha negra), membrana basal (BM), músculo liso (SM), plexo submucoso (PS), plexo mientérico (PM), vaso sanguíneo (BV), vaso linfático (LV), endotelio (En), tunica muscularis (TM) y lumen (*). Barra: $30 \mu \mathrm{m}$. 
la plica, y aisladas a lo largo de la plica, adyacentes a la membrana basal epitelial (Figuras 4A y 4E). En apariencia, estas células fueron más numerosas en la mitad craneal: alrededor de 4 o 5 células por grupo en comparación con una o 2 células agrupadas en la mitad caudal.

La tinción M-F se usó para la detección de moléculas en los gránulos de secreción capaces de reducir a la plata, técnica basada en la reacción argentafin (García del Moral, 1993). Se observaron grupos de células en el mismo número, posición y morfología que aquellas encontradas con la tinción de Grimelius (Figuras 4C, 4D, $4 G$ y $4 H)$.

Finalmente, para la distribución de MPS en las CC a lo largo del TGI se concluye de la siguiente manera: en la porción craneal, MPS neutros (Figura 2A), MPSA sulfatados (Figuras 2B, 2C, 2D y 2G) y MPS con ácido siálico (Figuras 2J y 2K); en la porción caudal, MPS neutros (Figura 3A) y MPS con ácido siálico (Figuras 3J y 3K).

\section{Discusión}

Histología

El borde estriado de la superficie apical de los enterocitos (Figuras $1 C, 1 D, 1 G$ y $1 H$ ) corresponde a la imagen microscópica de las microvellosidades, lo que sugiere que los enterocitos presentan el área de superficie incrementada para la absorción (Eichholz y Crane, 1965); sin embargo, es necesario confirmar esta percepción mediante microscopía electrónica.

Con respecto al epitelio de revestimiento, ninguna de las técnicas de tinción (Figuras 1A, 2A y $3 \mathrm{~A}$ ) mostró límites celulares paralelos a la membrana basal, lo que define a este epitelio de revestimiento como pseudoestratificado cilíndrico; también exige confirmación mediante microscopía electrónica. Este hallazgo es consistente con las descripciones realizadas en el TGI de un anfibio: el cecílido Typhlonectes venezuelensis (Martínez et al, 2004). Los autores proponen especular que el ID de las tortugas caguama pudiera llevar a cabo funciones respiratorias, basados en la peculiaridad del epitelio pseudoestratificado. .

En un inicio el análisis apuntaba hacia las células de Paneth, las enteroendócrinas y las caliciformes; pero solo se identificaron estas últimas, mismas que presentaron características histoquímicas que se discuten con mayor detalle más adelante.

La submucosa se evagina hacia la luz formando plicas (Figuras TA y IE). La presencia de plicas en el aparato digestivo es una característica relevante del ID de las tortugas caguama. En el caso de las tortugas marinas, las razones fisiológicas acerca de la existencia de plicas no está confirmado; no obstante, en el duodeno, macroscópicamente se advierten estructuras o elevaciones de la mucosa con la apariencia de panal; estas estructuras pueden contribuir, no sólo a la compactación del alimento, sino a la ampliación de la superficie de contacto, quizá por la ausencia de vellosidades intestinales en las tortugas (Wyneken, 2001).

Los múltiples ductos con la apariencia de vasos linfáticos es una característica significativa del ID de las crías de tortugas caguama. Una posibilidad de la existencia de estos ductos se explicaría por el transporte de quilomicrones a través de los vasos linfáticos (Tso y Balint, 1985). Los quilomicrones transportan colesterol (Tso y Balint, 1986) y las tortugas caguama son grandes consumidoras de colesterol (Kakizoe, 2004), quizá por su dieta rica en crustáceos (Ernst y Lovich, 2009). 


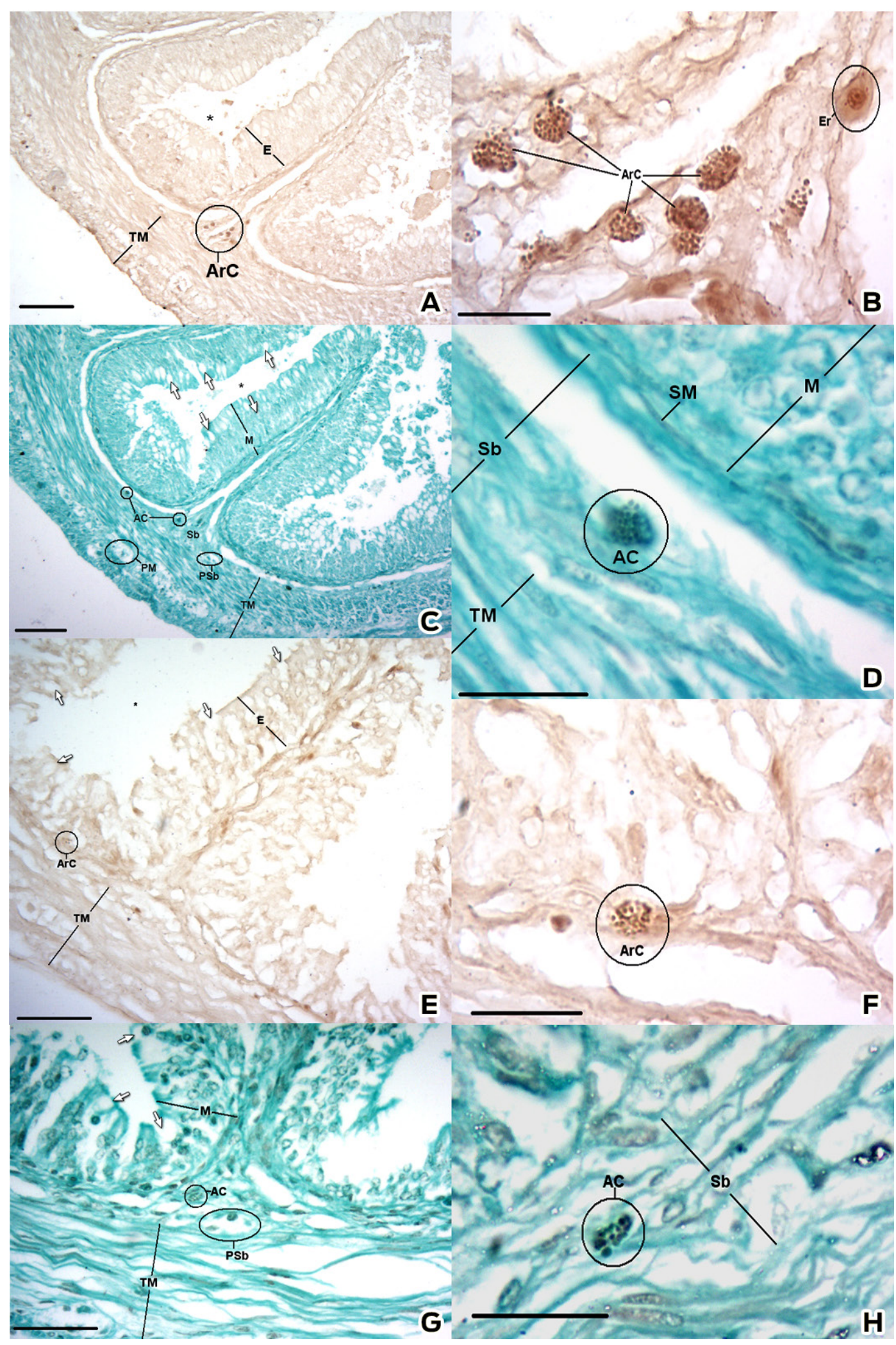

Figura 4. Resultados histoquímicos de las técnicas Grimelius y Masso-Fontana. Porción craneal: A y B) Tinción Grimelius, C y D) Tinción Masson-Fontana. Porción caudal: E y F) Tinción Grimelius, G y H) Tinción Masson-Fontana. Epitelio de revestimiento (E), mucosa (M), borde estriado (BB), célula caliciforme (flecha), célula argentafín (ArC), célula argirófila (AC), eritrocito (Er), submucosa (Sb), plexo submucoso (Psb), plexo mientérico (PM), vaso sanguíneo (BV), vaso

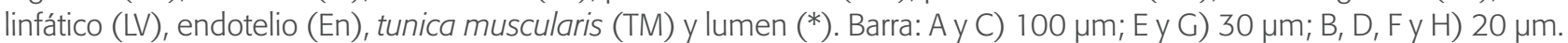


Los grupos de células pálidas observadas en la submucosa y en la muscular del órgano, entre el estrato circular y el longitudinal (Figuras IB y IF), pueden corresponder al plexo mientérico y submucoso, que actúan como moduladores importantes de la peristalsis y en la compactación del contenido intestinal (Holmberg et al, 2002). Timmermans et al, (1991) describieron la inervación entérica intrínseca en la tortuga de agua dulce Pseudemys scripta (ahora Trachemys scripta elegans); sin embargo, es inexiste la información al respecto en tortugas marinas para compararlas.

\section{Histoquímica}

La combinación de MPS se ha discutido como aspecto adaptativo (Park et al, 2001) que permite la lubricación y limpieza (Moitra et al, 1989) debido a la capacidad de favorecer las interacciones entre el agua y la mucosa (Singh et al, 1974). Rogers (1961) reportó que $1 \mathrm{~g}$ de MPSs puede asociarse con 200-500 g de agua.

La reacción metacromática tipo gamma en los gránulos de secreción de las CC en la porción craneal se relaciona con la presencia de componentes electronegativos (polianiones), en particular, ésteres sulfatados que favorecen la acumulación o polimerización de los componentes catiónicos de las tinciones Giemsa y AT (Pearse, 1960, García del Moral, 1993). Se ha sugerido que los MPSA, especialmente los MPSA sulfatados, forman una barrera de defensa que protege al intestino de patógenos potenciales y de las enzimas digestivas (Robertson y Wrigth, 1997). Es compatible con otros experimentos, los cuales indican que las CC de la región intestinal, densamente poblada con microorganismos, secretan principalmente mucinas ácidas (Nieuw et al, 1998). Más aún, los MPSA sulfatados muestran una mayor resistencia a la degradación por glicosidasa bacteriana, además de poseer un fuerte efecto inhibitorio en el crecimiento bacteriano comparado con los MPSA no sulfatados (Conour et al, 2002).

Por otro lado, la afinidad de los gránulos de secreción de las CC con la tinción MP está asociada a los aldehídos reactivos obtenidos después de una alta oxidación con ácido crómico, lo que revela tanto glucógeno como MPS neutros (Pearse, 1960). El glucógeno se ha reportado en las CC de ratas y se ha discutido el papel de la glucosa como precursor en la síntesis de otros carbohidratos en el aparato de Golgi (Neutra y Leblond, 1966). Las vesículas citoplásmicas constatadas con la tinción MP indican la posible presencia de cisternas del aparato de Golgi (Rambourg et al, 1969).

La naturaleza de las células con gránulos reactivos a las tinciones de impregnación de plata, Grimelius y M-F no se determinó por completo. Ahmed et al, (2009) evaluaron la técnica de Grimelius en el Varanus niloticus para demostrar la presencia de células enteroendócrinas, una variedad de célula epitelial. Más aún, en mamíferos, la reacción argentafin y argirófila se asocia con moléculas capaces de reducir el nitrato de plata, tales como las aminas biógenas (fundamentalmente 5-hidroxitriptamina y dopamina) (Lundqvist et al, 1990), que sintetizan los mastocitos (Kushnir-Sukhov et al, 2007) y las células enteroendócrinas (Grimelius, 2004). En la C. caretta, la localización de estas células en la submucosa y su morfología, podrían sugerir corresponden a mastocitos; sin embargo, los mastocitos son células típicamente reactivas al AT (Chiu y Lagunoff, 1972), hecho que no se observó en esta investigación. La posible presencia de otras células glandulares 
como las de Paneth es especulativo, ya que no se han reportado ni en otras tortugas, como en la tortuga Testudo graeca (Perez-Tomas et al, 1990), ni en otros reptiles (Ferri et al., 1976, Kotze et al 1992).

El hecho de que los animales analizados fueran crías complica la interpretación de los resultados. Al respecto, conviene llevar a cabo estudios inmunohistoquímicos complementarios, tanto para la investigación de mastocitos como de células de Paneth.

Los análisis de inmunohistoquímica, enfocados a determinar la existencia de células tales como linfocitos intraepiteliales, células dendríticas y linfocitos en migración, clarificarían los mecanismos de la inmunidad mucosal. También se recomienda indagar respecto a la fisiología de los quilomicrones, con investigaciones similares a las de Tso y Balint (1985). Cualquier exploración prospectiva requerirá una descripción histológica, por lo que este trabajo servirá de cimiento.

\section{Conclusiones}

El intestino delgado de las crías de tortugas caguama es un órgano peculiar, en especial por la pseudoestratificación del epitelio de revestimiento y los múltiples vasos linfáticos. Las diferencias histológicas e histoquímicas a lo largo del intestino delgado indican que las funciones realizadas por ambas porciones son diferentes. Por ejemplo, los mucopolisacáridos ácidos sulfatados, que forman una barrera de defensa contra los microorganismos, se hallan en la porción craneal. Es necesario que los resultados se comparen utilizando diversos grupos etarios.

Se han formulado hipótesis y se ha descubierto información nueva, tal como la posible función respiratoria; mas es indispensable pensar en futuras argumentaciones científicas, apoyándose en hallazgos ultraestructurales con microscopia electrónica. Del mismo modo, será necesario desarrollar técnicas complementarias para determinar la presencia de células de Paneth y enteroendócrinas. La lectin histoquímica podría elucidar la naturaleza bioquímica de los carbohidratos estudiados.

Finalmente, se comprenden las limitaciones de esta descripción en cuanto al número de individuos, los grupos etarios y la conservación de las muestras; no obstante se entiende como un valioso esfuerzo para la comprensión y aplicación del conocimiento histológico en la conservación de tortugas marinas.

\section{Financiamiento}

Esta investigación fue posible gracias al apoyo de la Dirección General de Asuntos del Personal Académico (DGAPA) de la Universidad Nacional Autónoma de México (UNAM), a través del proyecto PAPIIT IN216412.

\section{Agradecimientos}

Los autores agradecen a la Coordinación de Tortugas Marinas y Manatíes del Parque Eco-arqueológico Xcaret, a cargo de la MVZ Ana Negrete Philippe, por las faci- 
lidades ofrecidas para la realización de este trabajo. Agradecemos al histotecnólogo Emilio Francisco López López por su servicio en este proyecto.

\section{Conflictos de interés}

Santiago René Anzaldúa Arce es el jefe del Departmento de Morfología, Facultad de Medicina Veterinaria y Zootecnia. Los otros autores declaran que no tienen conflicto de interés.

\section{Contribución de los autores}

Rodrigo Ontiveros Tlachi: Realizó el trabajo de campo y el trabajo de laboratorio; analizó la información; colaboró en la redacción del manuscrito.

Fernando Alberto Muñoz Tenería: Dirigió el trabajo de campo; analizó la información. Santiago René Anzaldúa Arce: Contribuyó con nuevas técnicas analíticas y reactivos; dirigió el trabajo de laboratorio; analizó la información; colaboró en la redacción del manuscrito.

\section{Referencias}

1) Ahmed, Y.A., El-hafez, A.A.E. and Zayed, A.E. 2009. Histological and histochemical studies on the esophagus, stomach and small intestine of Varanus niloticus. Journal of Veterinary Anatomy. 2(1): 35-48.

2) Chiu, H. and Lagunoff, D. 1972. Histochemical comparison of vertebrate mast cells. Histochemical Journal. 4: 135-144.

3) Conour, J.E., Ganessunker, D., Tappenden, K.A., Donovan, S.M. and Gaskins, H.R. 2002. Acidomucin goblet cell expansion induced by parenteral nutrition in the small intestine of piglets. American Journal of Physiology: Gastrointestinal and Liver Physiology. 283: 1185-1196.

4) Davenport, J. and Clough, W. 1986. Swimming and Diving in Young Loggerhead Sea Turtles (Caretta caretta L). Copeia. 1: 53-57.

5) Eichholz, A. and Crane, R.K. 1965. Studies on the organization of the brush border in intestinal epithelial cells. Journal of Cell Biology. 26: 687-691.

6) Ernst, C.H. and Lovich, J.E. 2009. Turtles of the United States and Canada. $2^{\text {nd }}$ edition. Baltimore, Maryland, Estados Unidos de América: The Johns Hopkins University Press.

7) Ferri, S., Junqueira, L. C., Medeiros, L. F. and Mederios, L. O. 1976. Gross, microscopic and ultrastructural study of the intestinal tube of Xenodon merremii Wagler, 1824 (Ophidia). Journal of anatomy.121(2): 291-301.

8) García del Moral, R. 1993. Laboratorio de Anatomía Patológica. Madrid, España: McGraw-Hill-Interamericana de España.

9) Grimelius, L. 2004. Silver Stains demonstrating neuroendocrine cells. Biotechnic \& Histochemistry. 7(3): 7-44.

10) Holmberg, A., Kaim, J., Persson, A., Jensen, J., Wang, T. and Holmgren, S. 2002. Effects of digestive status on the reptilian gut. Comparative Biochemistry and Physiology Part A: Molecular \& Integrative Physiology. 133(3): 499-518.

11) Integrated Taxonomic Information System. 2000. Integrated Taxonomic Information System on-line database. Accessed 2013 Oct 23rd. http://www.itis.gov.

12) International Committee On Veterinary Gross Anatomical Nomenclature. 2012 Nomina Anatomica Veterinaria. Fifth edition. World Association of Veterinary Anatomist Editorial Committee. 
13) Kakizoe, Y., Sakaoka, K., Kakizoe, F., Yoshii, M., Nakamura, H., Kanou, Y. and Uchida I. 2007. Successive changes of hematologic characteristics and plasma chemistry values of juvenile loggerhead turtles (Caretta caretta). Journal of Zoo and Wildlife Medicine. 38(1): 77-84.

14) Kotze, S. H., Van der Merwe, N. J., Van Aswegen, G. and Smith, G. A. 1992. A light microscopical study of the intestinal tract of the Nile crocodile (Crocodylus niloticus Laurenti 1768). Onderstepoort Journal of Veterinary Research. 59: 249-252.

15) Kushnir-Sukhov, N.M., Brown, J.M., Wu, Y., Kirshenbaum, A. and Metcalfe D.D. 2007. Human mast cells are capable of serotonin synthesis and release. Journal of Allergy and Clinical Immunology. 119: 498-499.

16) Lundqvist, M., Arnberg, H., Candell, J., Malmgren, M., Wilander, E., Grimelius, L. and Öberg K. 1990 Silver stains for identification of neuroendocrine cells. A study of the chemical background. The Histochemical Journal. 22(11): 615-623.

17) Mc Manus, J.F.A. 1948. Histological and histochemical uses of periodic acid. Stain Technology. 23: 99-108.

18) Magalhaes, M dos S., Barsante Santos, A.J., Da Silva, N.B. and De Moura, C.E.B. 2012 Anatomy of the digestive tube of sea turtles (Reptilia: Testudines). Zoologia. 29(1): 70-76.

19) Martínez, T. Viloria, M., Camacho, J., Godoy, R., Herrera, E. and Muñoz, R. 2004. Aspectos histológicos del intestino de Typhlonectes venezuelensis (Amphibia: Gymnophiona, Typhlonectidae). Revista Cientifica. 13(3): 237-243.

20) Moitra, M., Singh, O.K. and Munshi, J.S.D. 1989. Microanatomy and cytochemistry of the gastro-respiratory tract of an air breathing cobitid fish, Lepidocephalicthys guntea. Japan Journal of Ichthyology. 36: 227-31.

21) Mowry, R.W. 1956. Alcian blue techniques for the histochemical study of acidic carbohydrates. Journal of Histochemistry and Cytochemistry. 4: 407.

22) Neutra, M. and Leblond, C.P. 1966. Synthesis of the carbohydrate of mucus in the golgi complex as shown by electron microscope radioautography of goblet cells from rats injected with glucose- $H^{3}$. The Journal of Cell Biology. 30(1): 119-136.

23) Nieuw, A.A.V., Bolscher, J.G.M., Bloemena, E. and Veerman, E.C. 1998. Sulfomucins in the human body. Journal of Biological Chemistry. 379: 1-18.

24) Park, J.Y., Kim, I.S. and Kim, S.Y. 2001. Morphology and histochemistry of the mud loach, Misgurnus mizolepis, in relation to cutaneous respiration. Korean Journal of Biological Sciences. 5: 303-308.

25) Pearse, A.G.E. 1960. Histoquímica, Teórica y Aplicada. Madrid, España: Aguilar.

26) Perez-Tomas, R., Ballesta, J., Madrid, J. F., Pastor, L. M. and Hernandez, F. (1990), Histochemical and ultrastructural study of the digestive tract of the tortoise Testudo graeca (Testudines). Journal of Morphology. 204: 235-245.

27) Pritchard, P.C.H. 1979. Encyclopedia of turtles. New Jersey, Estados Unidos: TFH.

28) Prophet, E.B. Mills, B. Arrington, J.B. and Sobin L.H. 1995. Métodos Histotecnológicos del Instituto de Patología de las Fuerzas Armadas de los Estados Unidos. Washington D.C., Estados Unidos: Registro de Patología de los Estados Unidos.

29) Rambourg, A., Hernandez, W. y Leblond C.P. 1969. Detection of complex carbohydrates in the golgi apparatus of rat cells. The Journal of Cell Biology. 40: 395-410.

30) Rambourg, A. 1971. Glycoproteins at the surface of animal cells. International Review of Cytology. 31: 57-114. 
31) Robertson, A.M. and Wright, D.P. 1997. Bacterial glycosulphatases and sulphomucin degradation. Canadian Journal of Gastroenterology. 11: 361-366.

32) Rogers, H.J. 1961. The structure and function of hyaluronate. The Biochemical Society Symposia. 20: 51-78.

33) Singh, B.R., Guha, G. and Munshi J.S.D. 1974. Mucous cells of the respiratory sac in an air-breathing fish, Saccobranchus fossilis (Bloch). La Cellulae. 70: 1-15.

34) Spotila, J.R. 2004. Sea Turtles: A Complete Guide to their Biology, Behavior, and Conservation. Maryland, Estados Unidos de América: The Johns Hopkins University Press and Oakwood Arts.

35) Thompson, S.M. 1980. A comparative study of the anatomy and histology of the oral cavity and alimentary canal of two sea turtles: the herbivorous green turtle Chelonia mydas and the carnivorous loggerhead turtle Caretta caretta (includes discussion of diet and digestive physiology). Tesis de Maestría. Townsville, Australia: James Cook University of North Queensland.

36) Timmermans,J.P., Scheuermann, D.W., Gabriel, R., Adriaensen, D., Fekete, E. and De Groodf-Lasseel, M.H.A. 1991. The innervation of the gastrointestinal tract of a chelonian reptile, Pseudemys scripta elegans. I. Structure and topography of the enteric nerve plexuses using neuron-specific enolase imnunohistochemistry. Histochemistry. 95: 397-402.

37) Tso, P., Pitts, V. and Granger, D.N. 1985. Role of lymph flow in intestinal chylomicron transport. American Journal of Physiology-Gastrointestinal and Liver Physiology. 249(1): 21-28.

38) Tso, P. and Balint, J.A. 1986. Formation and transport of chylomicrons by enterocytes to the lymphatics. American Journal of Physiology-Gastrointestinal and Liver Physiology. 250(6): 715-726.

39) Wyneken, J. 2001. The Anatomy of Sea Turtles. Florida, Estados Unidos de América: Department of Commerce NOOA.

40) Yamabayashi, S. 1987. Periodic acid-Schiff-Alcian Blue: A method for the differential staining of glycoproteins. The Histochemical Journal. 19(10-11): 565-571. 